\title{
First Reported Use of Radiofrequency Identification (RFID) Technique for Targeted Excision of Suspicious Axillary Lymph Nodes in Early Stage Breast Cancer - Evaluation of Feasibility and Review of Current Recommendations
}

\author{
WOLFRAM MALTER*, CHRISTIAN EICHLER*, BETTINA HANSTEIN, \\ PETER MALLMANN and JOHANNES HOLTSCHMIDT
}

\author{
Department of Obstetrics and Gynecology, Faculty of Medicine, University Hospital of Cologne, Cologne, Germany
}

\begin{abstract}
Background/Aim: The purpose of this study was to evaluate, whether radio frequency identification (RFID) labeling of axillary lymph nodes (LNS) for the use of targeted resection is feasible in primary breast cancer patients with suspicious LNs. Patients and Methods: We analyzed 10 consecutive patients where RFID technique was used for intraoperative detection of suspicious LNs without preceding neoadjuvant chemotherapy (NACT). We compared the specifics of these procedures to 10 consecutive sentinel lymph node biopsies (SLNB) in the cNO situation. Results: Intraoperative detection rate (DR) for the RFID-labeled target lymph node (TLN) was $100 \%$. Perioperative complications were infrequent and comparable to SLNB. Average time for location of the RFID labeled TLN was quicker than for the SLN. In $71.4 \%$ the chip bearing TLN equaled a SLN. Conclusion: The use of the RFID technique for intraoperative localization of axillary LNs for targeted excision seems feasible. RFID technique for targeted axillary dissection (TAD) following NACT should be investigated in a prospective manner.
\end{abstract}

The axillary nodal status has been of paramount importance for decisions on adjuvant therapies in early stage breast cancer for many decades. Since sentinel lymph node biopsy (SLNB) was developed, the axillary status can be accurately evaluated with significantly lower iatrogenic morbidity

This article is freely accessible online.

*These Authors contributed equally to this study.

Correspondence to: Johannes Holtschmidt, MD, Kerpener Strasse 34, 50931 Cologne, Germany. Tel: +49 2214784945, Fax: +49 2214783411, e-mail: johannes.holtschmidt@gmail.com

Key Words: Faxitron, LOCalizer ${ }^{\mathrm{TM}}$, radiofrequency identification device, RFID, breast cancer, axillary surgery, targeted axillary dissection, axillary staging, sentinel node biopsy. compared to historic operation techniques (1-7). Targeted axillary dissection (TAD) as a combination of SLNB and targeted excision of an initially affected lymph node (LN) to evaluate residual axillary disease after neoadjuvant chemotherapy (NACT) is proposed to replace axillary lymph node dissection (ALND) in patients with clinical complete remission of the axilla ( $\mathrm{ycN} 0)$ after NACT. A superior method for intraoperative identification and targeted excision of these LNs has not been identified yet.

While SLNB is the worldwide accepted gold standard for axillary staging in patients with initially unsuspicious LNs (cN0), recommendations on axillary staging and treatment for patients with suspicious LNs or even affected LNs proven by needle biopsy remain controversial. Patients with LNs of clinically unclear dignity upon first presentation, for long, had no access to less invasive axillary operation techniques and received therapeutic or diagnostic ALND. Nowadays nodal involvement can be ruled out preoperatively via core needle biopsy (CNB) (8). However, the false negative rate (FNR) of CNB of suspicious LNs is estimated to be around $20 \%$ (8) and the impression upon ultrasound can vary widely depending on the metric dimensions of the LN metastasis, which can lead to a far higher number of false negative clinical evaluations (9). LNs that were biopsied should therefore be labeled using marking devices as clips just as it is done with breast lesions. This approach of CNB and clip labeling of suspicious LNs is recommended in major guidelines beginning in 2014 (10-12) and are recommended irrespective of a following NACT. This way, patients with suspicious LNs and a negative CNB of these LNs can be offered a SLNB. The reason why this rather circuitous approach is favored in several major guidelines is to largely avoid any unbeneficial ALND in those patients that turn out to be truly LN negative upon histology (13-15). It is also advisable to resect also the clipped LN during SLNB to rule out a false negative CNB result (14). On the other hand, LN metastases that are histologically proven via 
CNB should be securely marked for later retrieval and reevaluation after NACT $(13,15)$. For the sake of semantic clarification, this clipped node is called target lymph node (TLN) further on.

As systemic treatments are getting more and more effective, even for patients with initially a $\mathrm{pN}+(\mathrm{CNB})$ status undergoing NACT, less invasive axillary staging procedures are achievable (16). Axillary pathologic complete remission (pCR) rates range from $40 \%$ to more than $70 \%$ for special subtypes (17-19). For patients with initially positive LNs and a pCR of the breast after NACT chances are almost $90 \%$ to be free of tumor residuals in their LNs as well (19). An ALND in this situation has most likely only diagnostic and no therapeutic effect. Unfortunately, attempts to use SLNB after NACT in these patients failed to display satisfactory FNRs $(17,20)$. Therefore, it is not advisable to try to identify the patients with a pCR of the axilla with SLNB alone after NACT. A new approach is the combination of SLNB and resection of the TLN after NACT, together called TAD (2125). TAD is of rising importance in patients with ycN0 status after NACT and subject of multiple current investigations. Initially, Caudle and colleagues showed that the combination of SLNB and resection of the TLN has an FNR clearly below the commonly accepted threshold of $10 \%$ (21). However, in their retrospective series, the targeted resection of the TLN was performed in a proportion of the cases. For part of the patients the TLN was identified postoperatively upon pathology in the ALND specimen.

The devices used for labeling of non-palpable TLNs in clinical practice are not regulated in clinical practice guidelines and include magnetic implants, radioactive iodine seeds, tattoo ink, ultrasound detectable titanium or nitinol clips (21-25). The radio frequency identification (RFID) technique was introduced this year in Europe for intraoperative detection of non-palpable lesions (26-28). Its use for the targeted resection of axillary LNs in any situation has not been reported until now. The purpose of this analysis was to demonstrate RFID labeling of axillary LNs for the use of targeted resection. Previous reports on the LOCalizer system displayed $100 \%$ DRs of non-palpable breast lesions $(26,28)$. Unlike most other technologies available, the LOCalizer probe displays the distance of the probe from the tag in real-time. This intelligent feature may offer the opportunity to further refine DRs of TAD and reduce iatrogenic trauma during axillary surgery.

\section{Patients and Methods}

We retrospectively analyzed all patients that were treated for primary early breast cancer with $\mathrm{cN}+$ at our institution. All of these patients had ipsilateral biopsy proven invasive breast cancer without distant metastases. Approval of local ethics committee was obtained and informed consent was obtained from all individual participants included in this analysis. All patients with initially suspicious LNs with contraindication against CNB that had targeted resection of these LNs instead of ALND for further histologic clarification were reviewed. The intention in these cases was to spare these patients with clinically unclear nodal status, who were also not suitable for CNB, from upfront ALND. All cases were analyzed according to the method that was used for TLN labelling. Ten cases with RFID placement in the TLN were identified and analyzed separately. All ten patients received preoperative marking of suspicious LNs using the Faxitron (Hologic, Inc. Company, Marlborough, MA, USA) LOCalizer ${ }^{\mathrm{TM}}$ chip combined with ultrasound guidance (GE Voluson E8 Expert, GE Healthcare Chicago, IL, USA). The procedure of RFID tag placement in suspicious axillary LNs and consecutive intraoperative detection and resection are displayed in Figure 1.

Standard RFID chip placement at our institution: For RFID chip placement, a $2 \mathrm{~mm}$ skin incision is required to facilitate the insertion of the applicator. Due to the resistance of the skin, the applicator should not be inserted without this preparatory step, as excessively forceful skin penetration with the applicator might be harmful to delicate structures of the axilla. At our institution, in general only the most suspicious LN, i.e. the TLN, is marked. As the slightly larger diameter of the RFID applicator causes resistance in the underlying subcutaneous tissue as well, movement of the desired structures, i.e. LNs, is possible. Continuous ultrasound surveillance during chip placement is recommended.

Surgical management: All surgical procedures were performed by experienced oncology breast surgeons only. In general, surgical management followed the principles of lymphadenectomy during SLNB. Handling of the probe to locate the TLN and tissue dissection are very similar to that in SLNB. During surgical axillary staging, the tagged TLN was located using the LOCalizer Reader. An advantage of RFID is that the device is coated in glass and does not hold the risk of thermal tissue damage in comparison to guidewire localization, as the transmission of thermal/electrical energy in guide wires can cause tissue or skin damage. For the same reason, the RFID tag should not be clamped directly as this may break the glass casing. The successful excision of the RFID tag was confirmed intraoperatively via specimen radiography (Biovision Faxitron) and additional SLNB was offered to these patients instead of ALND. Patients with tumor manifestation in the marked TLN received completion ALND in a subsequent procedure.

The technique of targeted resection of axillary LNs with the help of RFID tags would be beneficial if it would be feasible to securely retrieve the marked $\mathrm{LN}$ in a procedure with limited surgical trauma. As SLNB is the gold standard in surgical axillary staging, we compared these cases to 10 consecutive standard radiotracer-guided SLNBs at our institution.

\section{Results}

We identified 10 patients that had targeted $\mathrm{LN}$ resection using RFID technique between April and October 2019. Six out of 10 patients had a localization unsuitable for CNB and 4 out of 10 had objected to axillary CNB.

We compared these cases to 10 exemplary, consecutive SLNBs at our institution. As standard SLNB is performed nowadays after NACT, 8/10 patients received SLNB after 

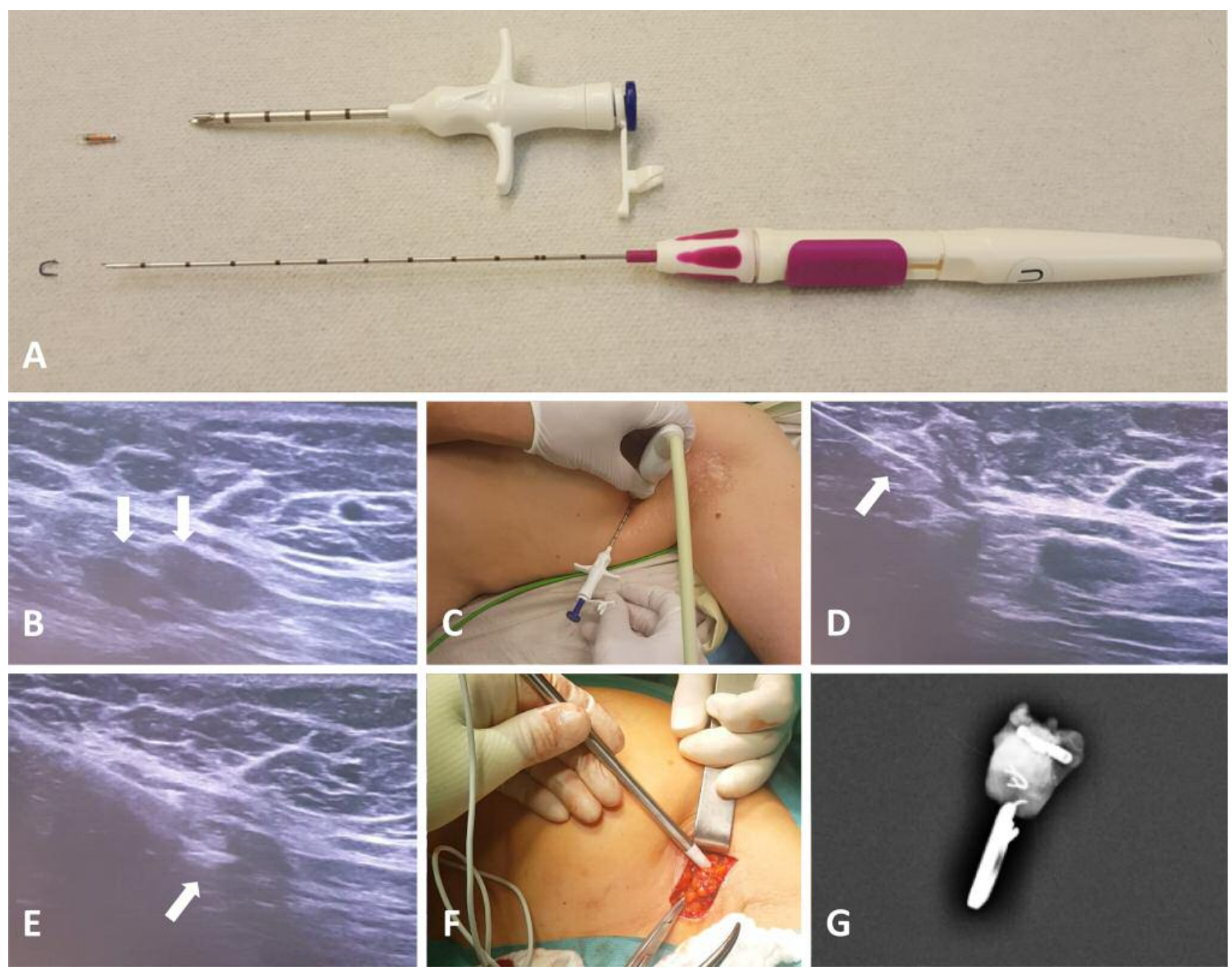

Figure 1. RFID tag placement and intraoperative retrieval. A: LOCalizer ${ }^{T M}$ RFID tag and applicator (above); Somatex Tumark ${ }^{\circledR}$ Professional; B: two suspicious lymph nodes (arrow); C-E: ultrasound guided tag application; D: needle placement (arrow); E: tag release (arrow); F: tag detection via axillary incision and LOCalizer ${ }^{\circledR}$ probe; G: intraoperative specimen radiography and confirmation of resection (specimen bears RFID tag and clip).

NACT. Other patient characteristics were comparable and are displayed in Table I. DR for the TLN with targeted RFID chip retrieval was $10 / 10(100 \%)$ as was DR for SLNB (10/10). In 7 of the $10 \mathrm{cN}+$ patients, the TLN turned out to be negative upon histology and axillary staging was completed with SLNB. In 5 of the 7 patients $(71.4 \%)$ with SLNB, the chip-bearing TLN equaled a SLN as it also featured radiotracer uptake. Three patients had a positive TLN, therefore received completion ALND. Perioperative procedural results are summarized in Table II. Compared with 10 exemplary SLNB cases, minor complications did not differ significantly, and no major complications were observed. The slightly higher rates for seroma/hematoma formation are explained by the need for completion ALND in three patients with affected TLN, whereas no patient received ALND in the control group. Mean time for detection of the TLN was $2.2 \mathrm{~min}$ and thereby was quicker than detection of the SLN (6 min on average; <0.01). In 5 of the 10 patients with TLNE the chip was located within the TLN. No chip was found further away than $5 \mathrm{~mm}$ from the TLN. In summary, all chips (100\%) were successfully excised during surgery and safety issues were not detected.

\section{Discussion}

The intraoperative identification of marked LNs in analogy to the targeted resection of non-palpable breast lesions requires further investigation. A method that warrants a secure detection of marked TLNs after a period of several months of NACT is needed for the implementation of TAD into daily routine. A 
Table I. Patient characteristics and performed axillary surgery in the two groups (TLNE versus SLNB).

\begin{tabular}{|c|c|c|c|c|c|}
\hline & $\begin{array}{l}\text { LOCalizer } \\
\text { TLNE }\end{array}$ & $\%$ & Control & $\%$ & $p$-Value \\
\hline Number of Cases & 10 & & 10 & & \\
\hline Gender (w) & 10 & & 10 & & \\
\hline Median age (Range) & $51.4(30-83)$ & & $59(41-82)$ & & 0.24 \\
\hline Median BMI (Range) & $26.5(22-35)$ & & $23.3(22-26)$ & & 0.1 \\
\hline Nicotine & $02 / 10$ & 20 & 0 & - & \\
\hline \multicolumn{6}{|l|}{ Menopausal Status } \\
\hline Pre & 4 & 40 & 3 & 30 & \\
\hline Post & 6 & 60 & 7 & 70 & \\
\hline \multicolumn{6}{|l|}{ N/A } \\
\hline \multicolumn{6}{|l|}{ Grading } \\
\hline G1 & 2 & 20 & 1 & 10 & \\
\hline G2 & 5 & 50 & 2 & 20 & \\
\hline G3 & 3 & 30 & 7 & 70 & 0.2 \\
\hline \multicolumn{6}{|l|}{ Histology } \\
\hline NST & 8 & 80 & 9 & 90 & \\
\hline Lobular & 1 & 10 & 1 & 10 & \\
\hline Other & 1 & 10 & - & - & 0.59 \\
\hline $\begin{array}{l}\text { Hormone receptor } \\
\text { positive }\end{array}$ & 10 & 100 & 5 & 50 & \\
\hline Her2neu positive & 0 & - & 1 & 10 & \\
\hline $\begin{array}{l}\text { Median Ki67 \% } \\
\text { (Range) }\end{array}$ & $32(5-70)$ & - & $37.3(8-80)$ & - & 0.67 \\
\hline \multicolumn{6}{|l|}{ Type of breast surgery } \\
\hline $\mathrm{BCS}$ & 7 & 70 & 5 & 50 & \\
\hline Mastectomy* & 3 & 30 & 5 & 50 & 0.65 \\
\hline \multicolumn{6}{|l|}{ Type of axilla surgery } \\
\hline SNLB $* *$ & 7 & 70 & 10 & 100 & 0.21 \\
\hline ALND & 3 & 30 & 0 & - & \\
\hline
\end{tabular}

TLNE: Target lymph node excision; BMI: body mass index; N/A not applicable; NST: no special type; BCS: breast conserving surgery; SLNB: sentinel lymph node biopsy; ALND axillary lymph node dissection. *Modified radical mastectomy or subcutaneous mastectomy; **Additional SLNB for patients with negative TLN; completion ALND for patients with positive TLN.

Dutch group recently reported DRs of up to $93 \%$ in a retrospective analysis (24). The intraoperative identification of the TLN was warranted using iodine seeds in the majority of the cases (24). Other small series have also shown acceptable DRs for the TLN ranging between $85-95 \%$ using clip marking or tattoo ink (22-25). However, the applicability of the very promising initial results by Caudle and colleagues in broad clinical practice has so far not been verified in a large scale, prospective manner. The so far largest prospective multicenter registry trial has lately reported a non-detection of the TLN in $22 \%$ of 473 patients/attempted resections (29). These colleagues used almost exclusively ultrasound detectable clips.

Each labeling method unfortunately bears specific disadvantages. Remission of axillary LN metastases after NACT results in normalization of LN structures. The contrast between the device and the initially hypo-echogenic, tumor infiltrated LN
Table II. Complication rates and results of TLNE versus SLNB. Successful chip retrieval during TLNE was 100\%. Detection of a SLN was as well 100\%. In $71.4 \%$, the TLN equaled a SLN (chip bearing LN also shows tracer uptake). Time to detection of the TLN was quicker than for $S L N B$.

\begin{tabular}{lccccc}
\hline & $\begin{array}{c}\text { LOCalizer } \\
\text { TLNE }\end{array}$ & Control & $\%$ & $p$-Value \\
\hline $\begin{array}{l}\text { Number of Cases } \\
\text { Minor complications }\end{array}$ & 10 & & 10 & & \\
$\quad \begin{array}{l}\text { Seroma } \\
\quad \text { Haematoma }\end{array}$ & 4 & 40 & 3 & 30 & 0.639 \\
$\quad$ (operative revision) & 1 & 10 & & - & - \\
$\begin{array}{l}\text { Major complications } \\
\text { Placement of RFID* }\end{array}$ & none & & none & & \\
$\quad$ in node & 5 & 50 & N/A & & \\
$\quad<5$ mm & 5 & 50 & N/A & & \\
$\quad>5$ mm & 0 & 0 & N/A & & 0.046 \\
$\begin{array}{l}\text { Average nodes } \\
\text { removed }\end{array}$ & $5.7(2-13)$ & & $2.9(1-5)$ & & \\
$\begin{array}{l}\text { Patients with } \\
\text { nodal involvement }\end{array}$ & 3 & $30 \%$ & 1 & $10 \%$ & \\
$\begin{array}{l}\text { Time to location } \\
\text { (minutes) }\end{array}$ & $2.2(0.5-4)$ & & $7.3(3-16)$ & $<0.01$ \\
$\begin{array}{l}\text { Failure to locate } \\
\begin{array}{l}\text { SNL equals TLN } \\
\hline\end{array}\end{array}$ & 0 & - & 0 & & \\
\hline
\end{tabular}

*RFID: Chip placement relative to lymph node. TLNE: Target lymph node excision; TLN: target lymph node; SLN: sentinel lymph node; RFID: radio frequency identification.

cortex is thereby diminished. This explains the difficulties of clip detection in ultrasound-navigated guidewire localization of clipmarked TLNs (29). Stereotactic guidewire placement can overcome this obstacle but requires the aid of a different department. It is usually performed by a radiologist and not by the breast surgeon, thereby slowing down the preoperative workflow. Moreover, it implies additional discomfort for the patients. Initial marking of TLNs with tattoo ink for later retrieval after NACT is a further option. As detection of tattooed LNs requires intraoperative visual exposition of the axillary tissue it may contradict the goal of trauma minimization (23). Moreover, migration of the tattoo ink over time into further nodes has been described (23). Therefore, a system that stays in place and transmits an active tracking signal for intraoperative localization, seems most desirable. Due to their radioactive nature, iodine seeds actively offer intraoperative information on their localization to the surgeon, but their use bears procedural and legal complexities for the same reason $(24,30)$.

To warrant the oncologic safety of TAD as a staging procedure, the TLN should be identified with a high sensitivity and resected in a procedure of limited surgical trauma. Furthermore, the ideal technique for TLNE should be easily available in clinical practice and avoid legal obstacles. For example, placement of iodine seeds for TLN 
localization is not feasible in Germany due to radiation protection legislature. Apart from the reliable intraoperative TLN detection, TAD requires a marker enduring several months of NACT without migration or dysfunction. As the optimal labeling technique has so far not been identified and in the absence of data on oncologic long-term outcomes, major guidelines give conflicting recommendations on the use of TAD as an alternative to ALND in ycN0 patients $(13,15,31,32)$. Thus, constantly rising remission rates, that have been accomplished through costly and exhausting systemic therapies, cannot be translated into less invasive axillary staging techniques nor into tailored local treatment. Apart from axillary surgical treatment, also decisions on radiation therapy (NSABP B51 ClinicalTrials.gov Identifier: NCT01872975) as well as post-neoadjuvant therapies (33) will presumably be based on the post-NACT axillary status in the future. Our results show that labeling and intraoperative identification of axillary LNs via the RFID technique might be a possible solution to this dilemma.

To our knowledge, the current series is the first description of RFID technology for localization of axillary LNs worldwide. A shortcoming is that SLNBs in the control group were performed in $80 \%$ of the cases after completion of NACT. Therefore, complication rates and healing conditions might be negatively altered in these patients. An obvious limitation is that we cannot state information on the stability of the RFID-labeling of LNs over a period of several months as is necessary for NACT. Only patients not undergoing NACT or planned for targeted resection of nonpalpable LNs for staging reasons before NACT were analyzed. Nonetheless, because of rapid intraoperative detection and $100 \%$ DR in our series, we deem future investigations on RFID use in TAD following NACT conceivable.

\section{Conclusion}

Data from this trial suggest that the RFID technique is an effective localization system for non-palpable axillary LNs intended for surgical removal. Unlike most other technologies available, the LOCalizer probe detects its distance from the tag and this intelligent feature may offer the opportunity to further reduce iatrogenic trauma during axillary surgery. Prospective trials are required to evaluate the sensitivity and specificity of distinct localization techniques in TAD after NACT as well as the oncologic outcomes of these patients.

\section{Conflicts of Interest}

W. Malter has received a speakers and consulting honoraria from Hologic Deutschland GmbH.

\section{Authors' Contributions}

Wolfram Malter: writing, editing, data collection, statistical analysis, trial development; Christian Eichler: writing, editing, data collection, statistical analysis, trial development; Bettina Hanstein: writing, editing; Peter Mallmann: writing, editing.

Johannes Holtschmidt: writing, editing, data collection, statistical analysis trial development.

\section{Acknowledgements}

The Authors would like to thank Faxitron for providing the LOCalizer $^{\mathrm{TM}}$ RFID system. Other funds were not received.

\section{References}

1 Veronesi U, Paganelli G, Viale G, Luini A, Zurrida S, Galimberti $\mathrm{V}$, Intra M, Veronesi P, Robertson C, Maisonneuve P, Renne G, De Cicco C, De Lucia F and Gennari R: A randomized comparison of sentinel-node biopsy with routine axillary dissection in breast cancer. N Engl J Med 349: 546-553, 2003. PMID: 12904519. DOI: 10.1056/NEJMoa012782

2 Mansel RE, Fallowfield L, Kissin M, Goyal A, Newcombe RG, Dixon JM, Yiangou C, Horgan K, Bundred N, Monypenny I, England D, Sibbering M, Abdullah TI, Barr L, Chetty U, Sinnett DH, Fleissig A, Clarke D and Ell PJ: Randomized multicenter trial of sentinel node biopsy versus standard axillary treatment in operable breast cancer: the ALMANAC Trial. J Natl Cancer Inst 98(9): 599-609, 2006. PMID: 16670385. DOI: 10.1093/jnci/ djj158

3 Fleissig A, Fallowfield LJ, Langridge CI, Johnson L, Newcombe RG, Dixon JM, Kissin M and Mansel RE: Post-operative arm morbidity and quality of life. Results of the ALMANAC randomised trial comparing sentinel node biopsy with standard axillary treatment in the management of patients with early breast cancer. Breast Cancer Res Treat 95(3): 279-293, 2006. PMID: 16163445. DOI: 10.1007/s10549-005-9025-7

4 NICE Clinical Guidelines, No. 80 - National Collaborating Centre for Cancer (UK). Early and Locally Advanced Breast Cancer: Diagnosis and Treatment (Internet). Cardiff (UK): National Collaborating Centre for Cancer (UK); 2009 Feb. Available at: http://www.ncbi.nlm.nih.gov/books/NBK11643 [Last accessed on 13 February 2020]

5 NZGG New Zealand Guidelines Group. Management of early breast cancer. Wellington: New Zealand Guidelines Group; 2009.

6 Ashikaga T, Krag DN, Land SR, Julian TB, Anderson SJ, Brown AM, Skelly JM, Harlow SP, Weaver DL, Mamounas EP, Costantino JP, Wolmark N and the National Surgical Adjuvant Breast, Bowel Project: Morbidity results from the NSABP B-32 trial comparing sentinel lymph node dissection versus axillary dissection. J Surg Oncol 102(2): 111-118, 2010. PMID: 20648579. DOI: $10.1002 /$ jso.21535

7 Rao R, Euhus D, Mayo HG and Balch C: Axillary node interventions in breast cancer: a systematic review. JAMA 310(13): 1385-1394, 2013. PMID: 24084924. DOI: 10.1001/ jama.2013.277804

8 Houssami N, Ciatto S, Turner RM, Cody HS $3^{\text {rd }}$ and Macaskill P: Preoperative ultrasound-guided needle biopsy of axillary nodes in invasive breast cancer: meta-analysis of its accuracy 
and utility in staging the axilla. Ann Surg 254(2): 243-251, 2011 PMID: 21597359. DOI: 10.1097/SLA.0b013e31821f1564

9 Stachs A1, Göde K, Hartmann S, Stengel B, Nierling U, Dieterich M, Reimer $\mathrm{T}$ and Gerber B: Accuracy of axillary ultrasound in preoperative nodal staging of breast cancer - size of metastases as limiting factor. Springerplus 2: 350, 2013. PMID: 23961414. DOI: 10.1186/2193-1801-2-350

10 Gradishar WJ, Anderson BO, Blair SL, Burstein HJ, Cyr A, Elias AD, Farrar WB, Forero A, Giordano SH, Goldstein LJ, Hayes DF, Hudis CA, Isakoff SJ, Ljung BM, Marcom PK, Mayer IA, McCormick B, Miller RS, Pegram M, Pierce LJ, Reed EC, Salerno KE, Schwartzberg LS, Smith ML, Soliman H, Somlo G, Ward JH, Wolff AC, Zellars R, Shead DA, Kumar R and the National Comprehensive Cancer Network Breast Cancer Panel: Breast cancer version 3.2014. J Natl Compr Canc Netw 12(4): 542-590, 2014. PMID: 24717572. DOI: 10.6004/jncen. 2014.0058

11 Untch M, Harbeck N, Huober J, von Minckwitz G, Gerber B, Kreipe HH, Liedtke C, Marschner N, Möbus V, Scheithauer H, Schneeweiss A, Thomssen C, Jackisch C, Beckmann MW, Blohmer JU, Costa SD, Decker T, Diel I, Fasching PA, Fehm T, Janni W, Lück HJ, Maass N, Scharl A and Loibl S: Primary therapy of patients with early breast cancer: Evidence, controversies, consensus opinions of German specialists to the 14th St. Gallen International Breast Cancer Conference 2015 (Vienna 2015). Geburtshilfe Frauenheilkd 75(6): 556-565, 2015. PMID: 26166836. DOI: 10.1055/s-0035-1546120

12 Bossuyt V, Provenzano E, Symmans WF, Boughey JC, Coles C, Curigliano G, Dixon JM, Esserman LJ, Fastner G, Kuehn T, Peintinger F, von Minckwitz G, White J, Yang W, Badve S, Denkert C, MacGrogan G, Penault-Llorca F, Viale G, Cameron $\mathrm{D}$ and the Breast International Group-North American Breast Cancer Group (BIG-NABCG) collaboration: Recommendations for standardized pathological characterization of residual disease for neoadjuvant clinical trials of breast cancer by the BIGNABCG collaboration, Ann Oncol 26(7): 1280-1291, 2015. PMID: 26019189. DOI: 10.1093/annonc/mdv161

13 NCCN Clinical Practice Guidelines in Oncology (NCCN Guidelines) Breast Cancer Version 3.2019 Sep 6, 2019. Available at https://www.ncen.org/professionals/physician_gls/pdf/breast.pdf [Last accessed on 13 February 2020]

14 S3 Leitlinie Mammakarzinom: Leitlinienprogramm Onkologie (Deutsche Krebsgesellschaft, Deutsche Krebshilfe, AWMF): S3Leitlinie Früherkennung, Diagnose, Therapie und Nachsorge des Mammakarzinoms, Version 4.1, 2018 AWMF Registernummer: 032-045OL. Available at: http://www.leitlinienprogrammonkologie.de/leitlinien/mammakarzinom [Last accessed on 13 February 2020]

15 AGO Empfehlungen gynäkologische Onkologie Kommission Mamma: Operative Therapie des Mammakarzinoms unter onkologischen Aspekten Version 2019.1D. Available at: https://www.ago-online.de/fileadmin/downloads/leitlinien/ mamma/2019-03/DE/einzel/2019D_08_Operative-Therapie-desMammakarzinoms-unter-onkologischen-Aspekten.pdf [Last accessed on 13 February 2020]

16 Mamtani A, Barrio AV, King TA, Van Zee KJ, Plitas G, Pilewskie M, El-Tamer M, Gemignani ML, Heerdt AS, Sclafani LM, Sacchini V, Cody HS 3rd, Patil S and Morrow M: How often does neoadjuvant chemotherapy avoid axillary dissection in patients with histologically confirmed nodal metastases? Results of a Prospective Study. Ann Surg Oncol 23(11): 3467-3474, 2016. PMID: 27160528. DOI: 10.1245/s 10434-016-5246-8

17 Boughey JC, Suman VJ, Mittendorf EA, Ahrendt GM, Wilke LG, Taback B, Leitch AM, Kuerer HM, Bowling M, FlippoMorton TS, Byrd DR, Ollila DW, Julian TB, McLaughlin SA, McCall L, Symmans WF, Le-Petross HT, Haffty BG, Buchholz TA, Nelson H, Hunt KK and the Alliance for Clinical Trials in Oncology: Sentinel lymph node surgery after neoadjuvant chemotherapy in patients with node-positive breast cancer: the ACOSOG Z1071 (Alliance) clinical trial. JAMA 310(14): 14551461, 2013. PMID: 24101169. DOI: 10.1001/jama.2013.278932

18 Dominici LS, Negron Gonzalez VM, Buzdar AU, Lucci A, Mittendorf EA, Le-Petross HT, Babiera GV, Meric-Bernstam F, Hunt KK and Kuerer HM: Cytologically proven axillary lymph node metastases are eradicated in patients receiving preoperative chemotherapy with concurrent trastuzumab for HER2-positive breast cancer. Cancer 116(12): 2884-2889, 2010. PMID: 20564395. DOI: $10.1002 / \mathrm{cncr} .25152$

19 Tadros AB, Yang WT, Krishnamurthy S, Rauch GM, Smith BD, Valero V, Black DM, Lucci A Jr, Caudle AS, DeSnyder SM, Teshome M, Barcenas CH, Miggins M, Adrada BE, Moseley T, Hwang RF, Hunt KK and Kuerer HM: Identification of patients with documented pathologic complete response in the breast after neoadjuvant chemotherapy for omission of axillary surgery. JAMA Surg 152: 665-670, 2017. PMID: 28423171. DOI: 10.1001/jamasurg.2017.0562

20 Kuehn T, Bauerfeind I, Fehm T, Fleige B, Hausschild M, Helms G, Lebeau A, Liedtke C, von Minckwitz G, Nekljudova V, Schmatloch S, Schrenk P, Staebler A and Untch M: Sentinellymph-node biopsy in patients with breast cancer before and after neoadjuvant chemotherapy (SENTINA): a prospective, multicentre cohort study. Lancet Oncol 14(7): 609-618, 2013. PMID: 23683750. DOI: 10.1016/S1470-2045(13)70166-9

21 Caudle AS, Yang WT, Krishnamurthy S, Mittendorf EA, Black DM, Gilcrease MZ, Bedrosian I, Hobbs BP, DeSnyder SM, Hwang RF, Adrada BE, Shaitelman SF, Chavez-MacGregor M, Smith BD, Candelaria RP, Babiera GV, Dogan BE, Santiago L, Hunt KK and Kuerer HM: Improved axillary evaluation following neoadjuvant therapy for patients with node-positive breast cancer using selective evaluation of clipped nodes: implementation of targeted axillary dissection. J Clin Oncol 34(10): 1072-1078, 2016. PMID: 26811528. DOI: 10.1200/JCO. 2015.64.0094

22 Flores-Funes D, Aguilar-Jiménez J, Martínez-Gálvez M, IbáñezIbáñez MJ, Carrasco-González L, Gil-Izquierdo JI, ChavesBenito MA, Ayala-De La Peña F, Nieto-Olivares A and AguayoAlbasini JL: Validation of the targeted axillary dissection technique in the axillary staging of breast cancer after neoadjuvant therapy: Preliminary results. Surg Oncol 30: 52-57, 2019. PMID: 31500785. DOI: 10.1016/j.suronc.2019.05.019

23 Natsiopoulos I, Intzes S, Liappis T, Zarampoukas K, Zarampoukas T, Zacharopoulou V and Papazisis K: Axillary lymph node tattooing and targeted axillary dissection in breast cancer patients who presented as $\mathrm{cN}+$ before neoadjuvant chemotherapy and became cNO after treatment. Clin Breast Cancer 19(3): 208-215, 2019. PMID: 30922804. DOI: 10.1016/ j.clbc.2019.01.013

24 Simons JM, van Pelt MLMA, Marinelli AWKS, Straver ME, Zeillemaker AM, Pereira Arias-Bouda LM5, van Nijnatten TJA, Koppert LB, Hunt KK, Smidt ML, Luiten EJT and van der Pol 
CC: Excision of both pretreatment marked positive nodes and sentinel nodes improves axillary staging after neoadjuvant systemic therapy in breast cancer. Br J Surg 106(12): 1632-1639, 2019. PMID: 31593294. DOI: 10.1002/bjs.11320

25 Coufal O, Zapletal O, Gabrielová L, Fabian P and Schneiderová M: Targeted axillary dissection and sentinel lymph node biopsy in breast cancer patients after neoadjuvant chemotherapy - a retrospective study. Rozhl Chir 97(12): 551-557, 2018. PMID: 30646734.

26 Malter W, Holtschmidt J, Thangarajah F, Mallmann P, Krug B, Warm $M$ and Eichler C: First reported use of the Faxitron LOCalizer $^{\mathrm{TM}}$ Radiofrequency Identification (RFID) system in Europe - A feasibility trial, surgical guide and review for nonpalpable breast lesions. In Vivo 33(5): 1559-1564, 2019. PMID: 31471405. DOI: 10.21873 /invivo.11637

27 Wazir U, Tayeh S, Perry N, Michell M, Malhotra A and Mokbel $\mathrm{K}$ : Wireless breast localization using radio-frequency identification tags: the first reported european experience in breast cancer. In Vivo 34(1): 233-238, 2020. PMID: 31882483. DOI: $10.21873 /$ invivo. 11765

28 DiNome ML, Kusske AM, Attai DJ, Fischer CP and Hoyt AC: Microchipping the breast: an effective new technology for localizing non-palpable breast lesions for surgery Breast Cancer Res Treat 175(1): 165-170, 2019. PMID: 30689105. DOI: 10.1007/s10549-019-05143-w

29 Reinisch M, Heil J, Rüland A, Seiberling C, Harrach H, Schindowski D, Lubitz J, Ankel C, Grasshoff ST, Deuschle P, Hanf V, Holtschmidt J, Traut E, Kuehn T and Kuemmel T: Prospective, multicenter registry trial to evaluate the clinical feasibility of targeted axillary dissection (TAD) in patients (pts) with breast cancer (BC) and core biopsy proven axillary involvement. Ann Oncol 30(5): v55-v98, 2019. DOI: 10.1093/ annonc/mdz240.003

30 van Nijnatten TJA, Simons JM, Smidt ML, van der Pol CC, van Diest PJ, Jager A, van Klaveren D, Kam BLR, Lobbes MBI, de Boer M, Verhoef K, Koppert LB and Luiten EJT: A novel lessinvasive approach for axillary staging after neoadjuvant chemotherapy in patients with axillary node-positive breast cancer by combining radioactive iodine seed localization in the axilla with the sentinel node procedure (RISAS): A Dutch Prospective Multicenter Validation Study. Clin Breast Cancer 17(5): 399-402, 2017. PMID: 28487053. DOI: 10.1016/j.clbc. 2017.04.006

31 Lyman GH, Temin S, Edge SB, Newman LA, Turner RR, Weaver DL, Benson AB 3rd, Bosserman LD, Burstein HJ, Cody H 3rd, Hayman J, Perkins CL, Podoloff DA, Giuliano AE and the American Society of Clinical Oncology Clinical Practice: Sentinel lymph node biopsy for patients with early-stage breast cancer: American Society of Clinical Oncology Clinical Practice Guideline Update. J Clin Oncol 32: 1365-1383, 2014. PMID: 24663048. DOI: $10.1200 /$ JCO.2013.54.1177

32 Lyman GH, Somerfield MR, Bosserman LD, Perkins CL, Weaver DL and Giuliano AE: Sentinel lymph node biopsy for patients with early-stage breast cancer: american society of clinical oncology clinical practice guideline update. J Clin Oncol 35(5): 561-564, 2017. PMID: 27937089. DOI: 10.1200/JCO. 2016.71.0947

33 von Minckwitz G, Huang CS, Mano MS, Loibl S, Mamounas EP, Untch M, Wolmark N, Rastogi P, Schneeweiss A, Redondo A, Fischer HH, Jacot W, Conlin AK, Arce-Salinas C, Wapnir IL, Jackisch C, DiGiovanna MP, Fasching PA, Crown JP, Wülfing P, Shao Z, Rota Caremoli E, Wu H, Lam LH, Tesarowski D, Smitt M, Douthwaite H, Singel SM, Geyer CE Jr and the KATHERINE Investigators: Trastuzumab emtansine for residual invasive HER2-positive breast cancer. N Engl J Med 380(7): 617-628, 2019. PMID: 30516102. DOI: 10.1056/NEJMoa1814017

Received February 27, 2020

Revised March 15, 2020

Accepted March 16, 2020 